\title{
Screening and Prediction of Erosive Potential
}

\author{
M.E. Barbour ${ }^{a} \quad$ A. Lussib ${ }^{b}$ R.P. Shellis $a, b$ \\ ${ }^{a}$ School of Oral and Dental Sciences, University of Bristol, Bristol, UK; ${ }^{b}$ Department of Preventive, \\ Restorative and Pediatric Dentistry, University of Bern, Bern, Switzerland
}

\section{Key Words}

Dental erosion - Dentine - Enamel - Erosive potential • Hydroxyapatite $\cdot$ Microhardness $\cdot$ Nanohardness $\cdot \mathrm{pH}$-stat Profilometry $\cdot$ Soft drinks

\begin{abstract}
The literature on the erosive potential of drinks and other products is summarised, and aspects of the conduct of screening tests as well as possible correlations of the erosive potential with various solution parameters are discussed. The solution parameters that have been suggested as important include $\mathrm{pH}$, acid concentration (with respect to buffer capacity and concentration of undissociated acid), degree of saturation, calcium and phosphate concentrations, and inhibitors of erosion. Based on the available data, it is concluded that the dominant factor in erosion is $\mathrm{pH}$. The effect of buffer capacity seems to be $\mathrm{pH}$ dependent. The degree of saturation probably has a non-linear relationship with erosion. While calcium at elevated concentrations is known to reduce erosion effectively, it is not known whether it is important at naturally occurring concentrations. Fluoride at naturally occurring concentrations is inversely correlated with erosive potential, but phosphate is probably not. Natural plant gums, notably pectin, do not inhibit erosion, so they are unlikely to interfere with the prediction of erosive potential. The non-linearity of some solution factors and interactions with $\mathrm{pH}$ need to be taken into account when de-
\end{abstract}

veloping multivariate models for predicting the erosive potential of different solutions. Finally, the erosive potential of solutions towards enamel and dentine might differ.

Copyright $\odot 2011$ S. Karger AG, Basel

At the population level, the most important extrinsic factors involved in dental erosion are products intended for consumption: fruit juices, soft drinks, wines, acidic foods such as pickles, some oral health products and some medications. Numerous products have been tested in vitro (screened) to determine which are erosive and, if so, to what extent. These tests provide standardised data on erosive potential, i.e. the extent of erosion that occurs in the absence of the numerous modifying factors which vary between individuals and between different occasions, such as the pattern and rate of salivary flow, salivary buffering and the properties of the acquired pellicle. Screening is valuable in understanding the aetiology of erosion, in interpreting epidemiological findings, and in making clinical assessments. Several studies have combined tests of erosion with analysis of the test products, with the aim of exploring correlations between erosive potential and individual chemical properties of the products. In principle, this information could enable the erosive potential of a product to be predicted from the analysis of key chemical properties. 
In this paper, the literature on the erosive potential of beverages and other products is first summarised, and the design and methodology of screening studies are discussed. Then, correlations between erosivity and chemical factors are described, and the prospects for the prediction of erosivity in vivo are discussed. Some explanatory material, in the form of two appendices, is available as online supplementary material (www. karger.com/doi/10.1159/000325917).

\section{Screening Products for Erosive Potential}

Screening tests are predominantly performed in vitro, and comparative information has shown that in vitro erosion is greater than in situ erosion under the same conditions [West et al., 2011]. Nevertheless, there is a good correlation between in vitro and in situ erosion [Hughes et al., 1999a; West et al., 1999], so in vitro measurements seem to provide reasonable estimates of relative erosivity. Moreover, it can be assumed that if a product is not erosive in vitro, it will not be erosive in vivo either [Lussi et al., 2000].

A large number of papers collectively contain extensive comparative data on erosive potential of beverages [Rytömaa et al., 1988; Larsen and Nyvad, 1999; Lussi et al., 2000; Parry et al., 2001; Mahoney et al., 2003; Lussi et al., 2004; Jensdottir et al., 2005, 2006; Hemingway et al., 2006; Lussi and Jaeggi, 2006; Brown et al., 2007; Hara and Zero, 2008; Jager et al., 2008]. Most screening models have tested erosive potential against enamel (either human or bovine), but Mok et al. [2001] and Mahoney et al. [2003] have studied erosive potential against dentine. Jensdottir et al. [2005] used pieces of teeth, which presumably presented both enamel and dentine for testing. Some studies have used hydroxyapatite (HA) dissolution as a model system [Parry et al., 2001; Jensdottir et al., 2006; Brown et al., 2007], either as the sole test system or as a supplement to studies on tooth tissue.

Comparison of results among studies is difficult, since variables that affect erosion rates significantly, such as stirring arrangements, temperature and volume of product per specimen, differ between studies and have sometimes not even been reported. Temperature and solution volume are easily controlled, but standardised stirring is somewhat more difficult to achieve, particularly when 'gentle agitation' is employed, since at low stirring rates, small variations in this rate can produce large variations in erosion [Shellis et al., 2005]. However, in recent years, methods of achieving reproducible and quantifiable stir- ring have been devised, e.g. by Attin et al. [2003] and Hemingway et al. [2008]. Standardisation of methodology would be a prerequisite step to provide sufficient information in publications to allow experiments to be repeated. To enable comparisons among studies, a standard challenge, for instance a defined citric acid solution, should be included in each study.

In most screening tests, a single exposure to the product(s) is performed, followed by immediate evaluation of erosion, but some studies used multiple exposures. Hara and Zero [2008] exposed different areas on the test surfaces for varying periods, while others subjected whole specimens to consecutive treatments [Parry et al., 2001; Lupi-Perugier et al., 2003; Hemingway et al., 2006], with intervening steps of washing, drying and measurement. Mok et al. [2001] went to some lengths to mimic the erosion process in wine tasters, using numerous repetitions of a 3-min cycle of exposure to wine, rinsing and drying. The advantage of using a series of repeated challenges is that it increases the chances of obtaining reliable results, since changes can be detected after multiple exposures, even if none is detectable after a single exposure. This approach is particularly useful when products with a wide range of erosive potential are compared. By using a range of exposure times, Hara and Zero [2008] obtained data on both softening and tissue loss for a group of drinks with a more than 10 -fold variation in the erosive potential.

Rehardening of surface-softened enamel or demineralised enamel by in vitro exposure to natural or artificial saliva has been reported [Collys et al., 1993; Eisenburger et al., 2001; Hara et al., 2008a]. However, pH-cycling models which include a remineralisation stage, like those common in cariology, have not been widely used. Rytömaa et al. [1988] found that storing specimens in natural saliva between consecutive erosive challenges had no significant effect on the ultimate tissue loss. Tantbirojn et al. [2008] and Panich and Poolthong [2009] noted that artificial saliva with near-neutral $\mathrm{pH}$ rehardened softened enamel neither after $24 \mathrm{~h}$ nor after $48 \mathrm{~h}$ of exposure, with or without addition of $1 \mathrm{mg} / \mathrm{l}$ fluoride [Tantbirojn et al., 2008], nor as part of a cycling model [Panich and Poolthong, 2009]. In contrast, Hara et al. [2008b] found that artificial saliva significantly reduced erosive tissue loss in enamel compared to water as a control. However, the effect of stimulated human saliva was not significantly different from that of water or of artificial saliva. Jensdottir et al. [2006] observed that, while pre-treatment of $\mathrm{HA}$ with saliva reduced erosion by about $50 \%$ at a $\mathrm{pH}$ of 2.5 , the effect was smaller as $\mathrm{pH}$ increased and there was 
no inhibition above a $\mathrm{pH}$ of 3.3. It seems unlikely that the discrepancies between these various reports could be due to the use of solutions with different degrees of saturation with respect to $\mathrm{HA}, S_{\mathrm{HA}}$ (online suppl. material). Collys et al. [1993] and Eisenburger et al. [2001], who reported partial remineralisation of softened enamel surfaces, studied solutions with an $S_{\mathrm{HA}}$ of 8.5-10.5 and 11.5, respectively. The solution used by Hara et al. [2008a] had an $S_{\mathrm{HA}}$ of 15.8, and Hara et al. [2008b] found that solutions with an $S_{\mathrm{HA}}<15.8$ did not consistently remineralise dentine lesions. The solution used by Tantbirojn et al. [2008] had an $S_{\mathrm{HA}}$ of 7.2, so it could have had too low a remineralisation potential, but that used by Panich and Poolthong was more highly saturated $\left(S_{\mathrm{HA}}=15.6\right)$, so it should have had a detectable effect on hardness. These conflicting results raise questions about the value of including exposure to saliva (natural or artificial) between acid exposures in short-term erosion experiments. In any case, it would certainly be necessary to check whether $S_{\mathrm{HA}}$ is $>1$ and to carry out preliminary tests on the artificial saliva to make sure that it does indeed support remineralisation: a commercially available artificial saliva chosen by Tantbirojn et al. [2008], for example, proved to be demineralising [see also Kielbassa et al., 2001; MeyerLueckel et al., 2002].

Studies on a variety of products [Rytömaa et al., 1988; Mahoney, 2003; Jensdottir et al., 2005, 2006; Lussi and Jaeggi, 2006; Jager et al., 2008] show that mineral water, beer and milk products are essentially non-erosive. In contrast, products with exceptionally high acid concentrations (vinegar, milk-derived lactic acid, or lemon juice concentrate) are highly erosive. Products with intermediate erosive potential include: fruit juices, sauces and purees; fruit-based soft drinks; colas; sports drinks; vitamin drinks; alcopops; citrus-flavoured tea, and wines. The rank order of products within this intermediate group varies between studies. For instance, Rytömaa et al. [1988] found cola to be more erosive than fruit-based drinks, but Lussi and Jaeggi's [2006] study revealed the reverse. This variation is not surprising, as no two studies have used the same combination of measurement techniques and experimental conditions. Jager et al. [2008] stated that the rank order of erosive potential depended on the analytical method (chemical analysis or profilometry). Jensdottir et al. [2006] reported that, while colas dissolved more HA over $30 \mathrm{~s}$ than orange drinks, some of the orange drinks showed a more sustained erosive effect over 30 min, so the ranking of erosive potential changed with exposure time.
A number of medications or other health care products, e.g. some vitamin preparations, are acidic and the erosive potential of some of these products has been investigated (see Hellwig and Lussi [2006] for review). An effervescent vitamin C tablet [Lussi and Jaeggi, 2006] seemed to reduce microhardness to a similar extent as fresh orange juice. An acidic sodium chlorite mouth rinse had a similar erosive potential, but that of other low-pH mouth rinses was $50-70 \%$ lower [Pontefract et al., 2001]. In other studies, many products with $\mathrm{pH}<6$ had such small effects on enamel that they could be considered safe for intra-oral use, but some products had a measurable erosive potential [Hellwig and Lussi, 2006; McNally et al., 2006]. However, interpretation of the clinical significance of such measurements could be hampered if the study did not include a product known to be erosive for comparison.

\section{Possible Factors Affecting Erosive Potential}

The relationship of a variety of chemical properties of products to their erosive potential has been extensively discussed. Attention has focused on $\mathrm{pH}$, buffer capacity, degree of saturation, calcium concentration, phosphate concentration and erosion inhibitors such as fluoride.

The interaction of several of these factors with the erosive process is markedly influenced by processes at the interface between the hard tissue and the eroding solution. The thin layer of solution closest to this interface is more or less static, even if the bulk of the solution is stirred. Transport of $\mathrm{H}^{+}$ions and dissolution products $\left(\mathrm{Ca}^{2+}\right.$ and $\mathrm{PO}_{4}^{3-}$ ions) through this layer - often referred to as the Nernst layer - is relatively slow because it is controlled by diffusion. Ion transport between the solution and the erosion front is also controlled by diffusion within the pores of the softened layer (enamel) or the outer demineralised collagen layer (dentine). As a result, the $\mathrm{pH}$ and the concentrations of calcium and phosphate at the site of erosion increase, leading to a raised degree of saturation and slower dissolution. Erosion depends on the rate of stirring [Shellis et al., 2005; Wiegand et al., 2007] because the thickness of the Nernst layer and the degree of saturation at the tooth-solution interface decrease when movement of the bulk solution is more rapid and vice versa. It is also because erosion is diffusion controlled that the process is affected by buffering and calcium concentration of erosive solutions (see below).

In the following, we first discuss data on the relative importance of the chemical factors noted above in rela- 
tion to enamel. Subsequently, we compare the properties of enamel and dentine as well as HA discs, which have been used in some studies.

\section{pH}

Although the $\mathrm{pH}$ of a solution influences the degree of saturation (by determining $\mathrm{PO}_{4}^{3-}$ and $\mathrm{OH}^{-}$ion activities), it is also an important independent factor in dissolution. Protonation of surface phosphate groups at low $\mathrm{pH}$ weakens co-ordination of the phosphate to the surrounding $\mathrm{Ca}^{2+}$ ions and hence destabilises the surface [Stumm, 1992].

Softening of enamel increases in a linear fashion in the pH range 6.3-2.9 [Barbour et al., 2003a], but the rate of tissue loss increases more steeply as $\mathrm{pH}$ falls [Davis and Winter, 1980; Larsen and Nyvad, 1999; West et al., 2001; Shellis et al., 2010]. In studies by Davis and Winter [1980] and Larsen and Nyvad [1999], enamel erosion was logarithmically related to $\mathrm{pH}$, and Jensdottir et al. [2006] found the same relationship for dissolution of HA powder.

Available data on beverages and simple acid solutions suggest that the threshold for detection of erosion (softening or tissue loss) by most methods is in the region of $\mathrm{pH}$ 5.0. Erosion by liquids with a $\mathrm{pH}$ as high as $6.3 \mathrm{can}$ be demonstrated, but requires the use of very high area/volume ratios [Parry et al., 2001] or long exposure times [McNally et al., 2006], or measurement by nanoindentation [Barbour et al., 2003a]. Yoghurts and some other milk products have a $\mathrm{pH}<5$ but are not erosive [Rytömaa et al., 1988; Lussi and Jaeggi, 2006] because they are saturated with respect to HA [Lussi and Jaeggi, 2006].

The erosion threshold of $\mathrm{pH} 5.0$ is based on empirical observations, not on the 'critical $\mathrm{pH}$ ', i.e. the $\mathrm{pH}$ at which a solution is saturated with respect to HA. Jensdottir et al. [2005] calculated critical $\mathrm{pH}$ values for a range of drinks and found values from 4.25 (milk) to 6.36 (energy drink), compared with 5.2-5.3 for stimulated whole saliva [Larsen and Pearce, 2003].

\section{Acid Type and Concentration (Buffering)}

Erosive products contain weak acids (e.g. citric, malic, phosphoric, and lactic acid). The concentration of the acid(s) determines not only the $\mathrm{pH}$ but also the buffering properties. The effects of acid concentrations on erosion can be considered from three viewpoints:

(1) Enhancement of Erosive Conditions at the Tooth Surface. A well-buffered solution will be able to maintain a higher $\mathrm{H}^{+}$concentration (lower $\mathrm{pH}$ ) in the Nernst layer than a poorly buffered solution with the same bulk $\mathrm{pH}$. Consequently, the degree of saturation at the tissue surface will be reduced and dissolution will be faster.

(2) Enhancement of Erosive Conditions beneath the Tooth Surface. In both enamel and dentine, the advancing front of the erosive lesion lies beneath the surface. At a low $\mathrm{pH}$, a high proportion of the weak acids in erosive products tends to be in the undissociated form which, being uncharged, could act as mobile buffers, delivering $\mathrm{H}^{+}$to the demineralising front [Gray, 1962; Featherstone and Rodgers, 1981].

(3) Prolongation of Erosion in vivo. In the mouth, a major factor affecting erosion is the neutralisation of an erosive product by salivary buffers, and this process will take longer for well-buffered products.

Two measures of buffering power have been used in erosion research. The titratable acidity (TA) is the amount of strong base required to raise the $\mathrm{pH}$ of a liquid from its native $\mathrm{pH}$ to a pre-defined value, typically 5.5 or 7.0. The results are often reported in millilitre of added base but should be converted to $\mathrm{mmol} / \mathrm{l}$, as TA is a concentration.

The classical buffer capacity, $\beta$ [Jensdottir et al., 2005; Barbour and Shellis, 2007], measures the resistance of the solution to change from its native $\mathrm{pH}$ and can be calculated from the solution composition or determined from the slope of a titration curve. Barbour and Shellis [2007] used the term 'differential buffer capacity' for $\beta$ in order to emphasise the difference from TA, which is an integrated buffer capacity between two defined $\mathrm{pH}$ values. Because of this difference, it seems appropriate to use $\beta$ when considering erosion in systems where $\mathrm{pH}$ is controlled or changes little, and to use TA in relation to situations where $\mathrm{pH}$ changes. The latter can include screening tests which use long exposure times or small volumes of erosive liquid in relation to the specimen area. Changes in $\mathrm{pH}$ during erosion are, of course, characteristic of intra-oral erosion, and TA might be a useful parameter for evaluating buffering power of an erosive product in vivo. However, for this purpose, the upper $\mathrm{pH}$ for the determination of TA should be appropriate for the sensitivity of the technique applied to measure erosion. In our opinion, the upper $\mathrm{pH}$ should be that at which erosion ceases to be detectable by most techniques: $\mathrm{pH} 5.0$ (or $\mathrm{pH}$ 5.5 to be on the safe side; see above). Titration to $\mathrm{pH}>5.5$, i.e. into a $\mathrm{pH}$ range where erosion is probably not clinically significant, adds no useful information.

Barbour and Shellis [2007] found that $\beta$ had a more consistent relationship to very early enamel softening than the concentration of undissociated acid. 


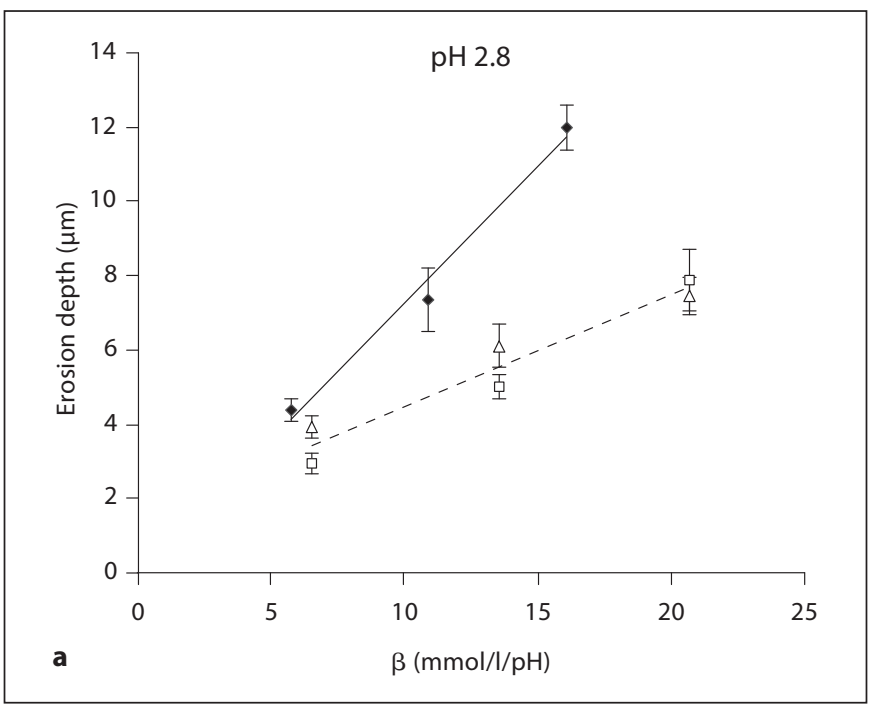

Fig. 1. Erosion of enamel in relation to buffer capacity $(\beta)$ at $\mathrm{pH}$ 2.8 (a), pH 3.3 (b) and pH 3.8 (c). Re-analysis of the data of Hughes et al. [2000]. Open triangles $=$ Citric acid; open squares $=$ malic acid; solid diamonds = lactic acid. Common trend line fitted to citric and malic data.

The enamel dissolution rate in citric acid shows a strong response to $\beta$ at $\mathrm{pH} 2.45$, a smaller response at $\mathrm{pH} 3.2$, and no statistically significant response at pH 3.9 [Shellis et al., 2010]. This result is supported by a re-analysis of data on enamel erosion in three acids at different concentrations and $\mathrm{pH}$ values [Hughes et al., 2000], which showed that buffer capacity had more effect on erosion as the $\mathrm{pH}$ fell from 3.8 to 2.8 (fig. 1). A further result of interest was that $\mathrm{pH}$ had a much greater effect on erosion depth in lactic acid than in citric and malic acids. The enhanced erosive potential of lactic acid at low $\mathrm{pH}$ (fig. 1) could be due to more of it being in the undissociated form (because of its relatively high $\mathrm{pK}_{\mathrm{a}}$ ) which, because of its relatively small molecular size, would act as an effective mobile buffer.
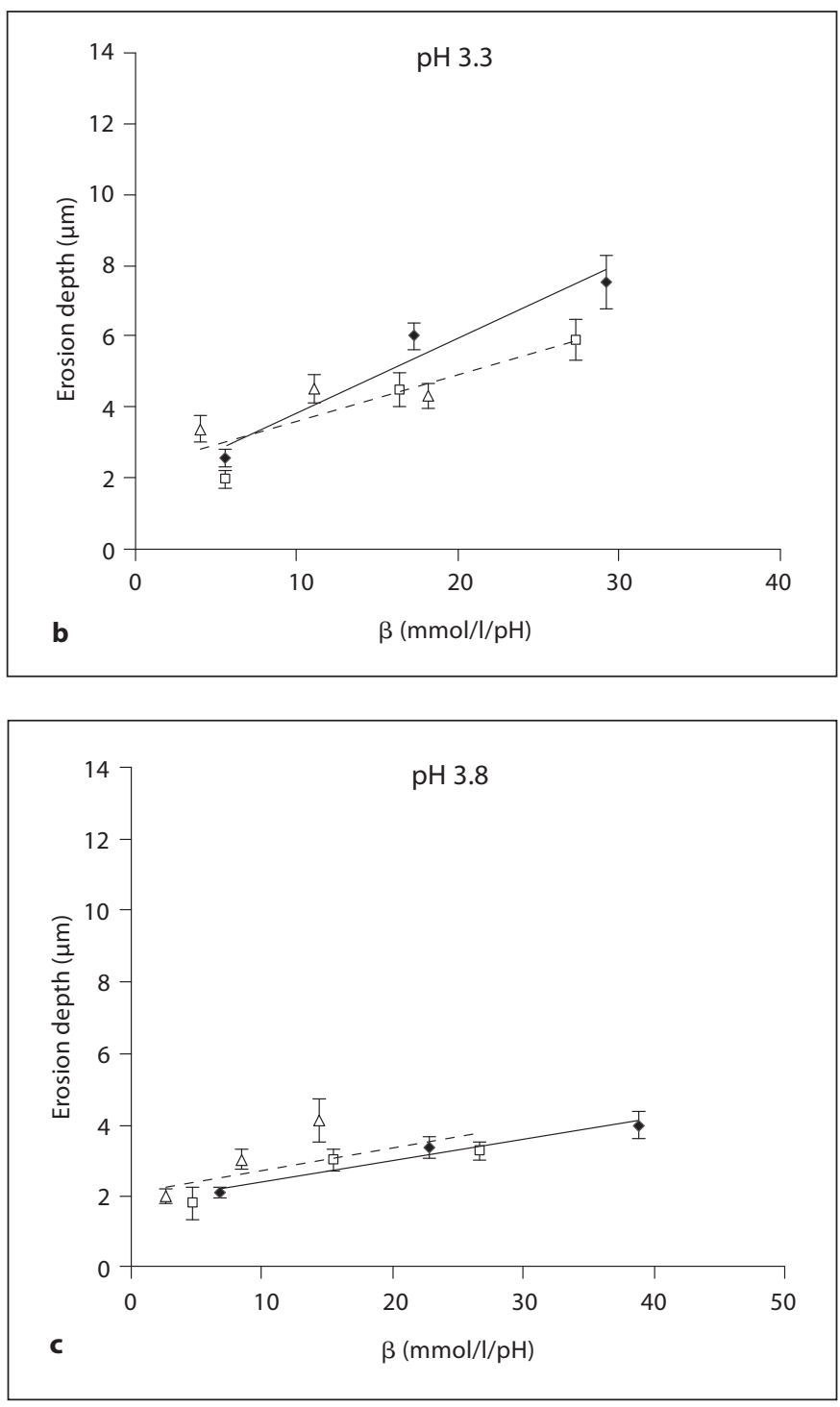

Several authors have found a strong correlation between TA and erosive potential [Lussi et al., 1995; Jensdottir et al., 2005], and Jensdottir et al. [2006] attributed the more prolonged erosive capacity of orange drinks compared to that of colas to their greater TA. However, other authors have not confirmed this correlation [Larsen and Nyvad, 1999; Mahoney et al., 2003; Hemingway et al., 2006]. One could speculate that in vivo, when only some small, unstirred remnants of an erosive solution are present (e.g. on the cupped occlusal surfaces), the TA is an important factor, but when an excess of an erosive agent is present, the $\mathrm{pH}$ is probably a more decisive factor. 


\section{Degree of Saturation}

The degree of saturation is the basic thermodynamic driving force for dissolution and crystal growth reactions. In dental research, because it has not proved possible to define solubilities of dental minerals in terms of their compositions, the degree of saturation is calculated in relation to HA. Three points should be considered when interpreting results.

First, because erosion is at least partly a diffusion-controlled process (see above), the degree of saturation in the bulk solution, which is calculated from electrolyte analysis, is not that which directly controls the rate of dissolution.

Second, the degree of saturation only helps to determine whether dissolution is possible, i.e. thermodynamically feasible. If a solution is supersaturated, dissolution is not possible. Thus, yoghurts tend to be supersaturated with respect to HA and are non-erosive [Lussi and Jaeggi, 2006]. In contrast, because a solution is undersaturated, it cannot be assumed that it will be erosive, since many factors, including low fluid movement, too low a temperature, unfavourable surface properties of the solid and the presence of inhibitors, can prevent or slow dissolution in an undersaturated solution.

Third, there is not a simple linear relationship between the degree of saturation and the dissolution rate [Blum and Lasaga, 1987]. In slightly or moderately undersaturated solutions, the rate of dissolution will increase as the degree of saturation falls, but eventually the dissolution rate will reach a plateau and will not respond to further falls in the degree of saturation [Blum and Lasaga, 1987]. Because many erosive liquids contain little or no calcium or phosphate, they are highly undersaturated, and it is possible that, below a certain degree of saturation, quite wide variations in the degree of saturation would have little, if any, effect on the dissolution rate. A preliminary estimate of the cut-off point can be made from $\mathrm{pH}$-stat data. After an initial adjustment period, the dissolution rate of enamel or HA is constant [Shellis et al., 2010], indicating that, although calcium and phosphate are accumulating in the solution, the degree of saturation does not reach the point where it affects the dissolution rate. Using our dissolution rate data, we have calculated the maximum degree of saturation reached at the end of our experimental period (at least $30 \mathrm{~min}$ ); it was about 0.0047 $(\mathrm{pK}-\mathrm{pI}=-20.95)$. In solutions with a lower saturation than this, the degree of saturation might not affect the dissolution rate.

\section{Calcium and Phosphate Concentrations}

The presence of calcium alone in an erosive solution can modify the dissolution rate, even though the degree of saturation in the bulk solution is zero. This is because calcium raises the degree of saturation in the Nernst layer by augmenting the number of calcium and phosphate ions diffusing from the solid surface. At a constant degree of saturation, erosion increases as the calcium/phosphate ratio increases [Barbour et al., 2003b]. Modification of drinks by addition of calcium at relatively high concentrations $(5-10 \mathrm{mmol} / \mathrm{l})$ reduces erosivity successfully [Hughes et al., 1999b]. In such drinks, because $\mathrm{CaCO}_{3}$ is used to raise calcium concentration, there is also a rise in $\mathrm{pH}$, which adds to the effect of calcium.

McDonald and Stookey [1973] and Attin et al. [2003] suggested that addition of phosphate to erosive drinks or acid solutions also reduces erosive potential. In contrast, Hemingway et al. [2006] found no correlation between phosphate concentrations and the erosive potential of soft drinks and suggested that such a correlation was unlikely as, at the $\mathrm{pH}$ of erosive drinks, the proportion of total phosphate in the form of $\mathrm{PO}_{4}^{3-}$ ions (which influences the degree of saturation) is extremely low. In unpublished $\mathrm{pH}$-stat experiments, we have found no significant effect of 10 or $20 \mathrm{mmol} / \mathrm{l}$ phosphate on enamel erosion at $\mathrm{pH} 2.5,3.25$ or 4.0. Therefore, in previous studies, the $\mathrm{pH}$ was probably increased through addition of phosphate salts, and this increase in $\mathrm{pH}$ reduced the dissolution rate, and not the addition of phosphate.

\section{Inhibitors of Erosion}

Larsen [2001] and Larsen and Richards [2002] observed reductions in erosion of up to $46 \%$ due to fluoride dissolved in acid solutions, but the solutions were saturated with respect to calcium fluoride, so the fluoride concentrations were very high $(7-25 \mathrm{mg} / \mathrm{l})$. Low fluoride concentrations in erosive products will probably have proportionately smaller effects. The scant literature does not provide evidence as to how fluoride might act. It is possible that fluoride raises the degree of saturation with respect to fluorapatite in the same way as calcium raises the degree of saturation with respect to HA (see above).

Because several polymers have been shown to inhibit erosion at low concentrations [Barbour et al., 2006], it is possible that natural polymers in soft drinks might reduce the erosive potential. This could reduce the validity of predictions from electrolyte analyses. However, the major plant gum likely to occur in fruit-based drinks (pectin) does not significantly inhibit erosion [Barbour et al., 2006].

Caries Res 2011;45(suppl 1):24-32 


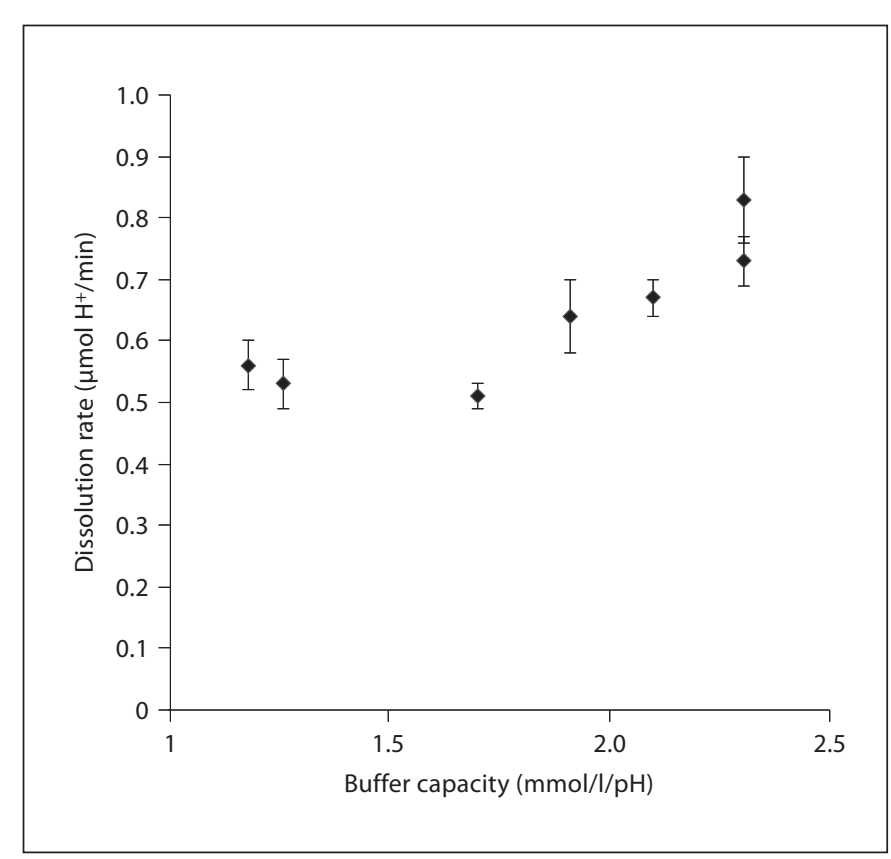

Fig. 2. Dissolution rate of compressed HA discs in a range of acids at $\mathrm{pH} 3.3$, plotted against buffer capacity. All acids were at concentrations which gave $\mathrm{pH} 3.3$, without addition of acid or base, so the concentrations and hence buffer capacity varied. From the left the acids are: hydrochloric, phosphoric, citric, malic, acetic, lactic and propionic acid.

\section{Comparison of Substrates}

Enamel and dentine show qualitative and quantitative differences which affect results on the erosive potential. Whereas the rate of enamel dissolution is essentially constant, that of dentine decreases progressively with time [Shellis et al., 2010], undoubtedly because an increasingly thick layer of demineralised collagen forms at the dentine surface and progressively restricts diffusion of $\mathrm{H}^{+}$and mineral ions, leading in turn to a reduced rate of mineral loss.

There is evidence that dentine mineral is more soluble than enamel mineral [Shellis, 1996], but this is not necessarily reflected in the relative susceptibilities of both tissues to erosion. The available evidence, from both profilometric and $\mathrm{pH}$-stat work [Shellis et al., 2010], suggests that there is less erosion of dentine than of enamel at a low $\mathrm{pH}$ (about 2.5), that at an intermediate $\mathrm{pH}$ (about 3.2) erosion in the two tissues is similar, and that it is only at a high $\mathrm{pH}$ (about 4.0) that dentine erosion exceeds enamel erosion. These results seem to be due to the variation in $\mathrm{pH}$ in the interactions between solubility, diffusion and tissue structure [Shellis et al., 2010]. It appears that the dissolution rate of dentine is less sensitive to both $\mathrm{pH}$ and to buffer capacity than that of enamel [Shellis et al., 2010], but further work is required.

Discs of compressed HA have been used as substrates in tests of erosion inhibitors [Barbour et al., 2006] and could be useful in other areas of erosion research. However, they differ quantitatively from dental tissues. We found that the dissolution rate of compressed HA was slower than that of either enamel or dentine and varied less with $\mathrm{pH}$ [Shellis et al., 2010]. The rate was not influenced by a buffer capacity above $7.3 \mathrm{mmol} / \mathrm{l} / \mathrm{pH}$, but Barbour [unpubl. data] found that the dissolution rate increased with buffer capacity up to $2.3 \mathrm{mmol} / \mathrm{l} / \mathrm{pH}$ (fig. 2) and so might reach a maximum at a very low buffer capacity.

\section{Prediction of Erosive Potential}

Correlations between chemical properties of products and erosive potential are particularly important since they might allow erosive potential to be predicted from chemical analysis of products. For practical purposes, it is desirable that the most important factors are identified, so that predictive tests can be restricted to those which yield the most information. Some studies have identified bivariate correlations between individual chemical properties and erosive potential [Mahoney et al., 2003; Jensdottir et al., 2005]. However, as Lussi and Jaeggi [1995] remarked, this approach can be misleading because of the possible interactions between variables, and a multivariate approach should be adopted.

Lussi et al. [1993] examined 14 drinks of various kinds. A multivariate statistical analysis suggested that $\mathrm{pH}$, TA, phosphate concentration and fluoride concentration (but not calcium concentration) were significantly associated with softening $\left(\mathrm{R}^{2}=0.81\right)$. A later study [Lussi et al., 1995] suggested that this regression model had a useful predictive value for erosive potential of drinks. Such models could undoubtedly be further improved. A review of the data indicates that in order to render regression models more realistic, non-linear relationships between some of the solution variables, especially the interactions with $\mathrm{pH}$, should be taken into account. It is also likely that a model that provides accurate predictions for enamel erosion might not be applicable to dentine. 


\section{Conclusions}

The following points can be summarised regarding the action of erosive drinks:

- The dominant factor in erosive dissolution is $\mathrm{pH}$;

- Buffer capacity and fluoride concentration can have significant effects on erosive potential against enamel, but the effects are $\mathrm{pH}$ dependent. Likewise, the degree of saturation probably affects the rate of dissolution only over a certain range and the rate will probably reach a maximum at a limiting degree of saturation (possibly <0.005). Calcium added to drinks at 5-10 $\mathrm{mmol} / \mathrm{l}$ strongly reduces erosive potential;

- The evidence with respect to phosphate is contradictory, but on balance it is unlikely to reduce erosive potential. Pectin, the plant gum most likely to occur in soft drinks, does not inhibit erosion;
- Dentine dissolution is less dependent on $\mathrm{pH}$ and buffer capacity than enamel dissolution, and it does not necessarily erode faster;

- Compressed HA discs differ structurally from the dental tissues, thus they are only suitable for chemical analysis of erosion and differ quantitatively in dissolution behaviour, but they are useful models for preliminary work on erosion.

\section{Disclosure Statement}

There are no conflicts of interest for any of the authors.

\section{References}

Attin T, Meyer K, Hellwig E, Buchalla W, Lennon ÁM: Effect of mineral supplements to citric acid on enamel erosion. Arch Oral Biol 2003;48:753-759.

-Barbour ME, Shellis RP: An investigation using atomic force microscopy nanoindentation of dental enamel demineralization as a function of undissociated acid concentration and differential buffer capacity. Phys Med Biol 2007;52:899-910.

- Barbour ME, Finke M, Parker DM, Hughes JA, Allen GC, Addy M: The relationship between enamel softening and erosion caused by soft drinks at a range of temperatures. J Dent 2006;34:207-213.

- Barbour ME, Parker DM, Allen GC, Jandt KD: Human enamel dissolution in citric acid as a function of $\mathrm{pH}$ in the range $2.30 \leq \mathrm{pH} \leq$ 6.30: a nanoindentation study. Eur J Oral Sci 2003a;111:258-262.

- Barbour ME, Parker DM, Jandt KD: Enamel dissolution as a function of solution degree of saturation with respect to hydroxyapatite: a nanoindentation study. J Colloid Interface Sci 2003b;265:9-14.

Blum AE, Lasaga AC: Monte Carlo simulations of surface reaction rate laws; in Stumm W (ed): Aquatic Surface Chemistry. Chemical Processes at the Particle-Water Interface. New York, Wiley, 1987, pp 255-292.

- Brown CJ, Smith G, Shaw L, Parry J, Smith AJ: The erosive potential of flavoured sparkling water drinks. Int J Paediatr Dent 2007;17:8691.

Collys K, Cleymaet R, Coomans D, Michotte Y, Slop D: Rehardening of surface softened and surface etched enamel in vitro and by intraoral exposure. Caries Res 1993;27:15-20.
Davis WB, Winter PJ: The effect of abrasion on enamel and dentine after exposure to dietary acid. Br Dent J 1980;148:253-256.

- Eisenburger M, Hughes JA, West NX, Shellis RP, Addy M: Use of ultrasonication to study remineralisation of eroded enamel. Caries Res 2001;35:61-66.

Featherstone JD, Rodgers BE: Effect of acetic, lactic and other organic acids on the formation of artificial caries lesions. Caries Res 1981;15:377-385.

Gray JA: Kinetics of the dissolution of human dental enamel in acid. J Dent Res 1962;41: 633-645.

Hara AT, Zero DT: Analysis of the erosion potential of calcium-containing acidic beverages. Eur J Oral Sci 2008;116:60-65.

-Hara AT, González-Cabezas C, Creeth J, Zero DT: The effect of saliva substitutes in an erosion-abrasion cycling model. Eur J Oral Sci 2008a;116:552-556.

Hara AT, Karlinsey RL, Zero DT: Dentine remineralization by stimulated saliva formulations with different $\mathrm{Ca}$ and $\mathrm{P}$ contents. Caries Res 2008b;41:51-56.

-Hellwig E, Lussi A: Oral hygiene products and acidic medicines; in Lussi A (ed): Dental Erosion. From Diagnosis to Therapy. Monogr Oral Sci. Basel, Karger, 2006, vol 20, pp 112118.

Hemingway CA, Parker DM, Addy M, Barbour ME: Erosion of enamel by non-carbonated soft drinks with and without toothbrushing abrasion. Br Dent J 2006;201:447-450.
Hemingway CA, Shellis RP, Parker DM, Addy M, Barbour ME: Inhibition of hydroxyapatite dissolution by ovalbumin as a function of $\mathrm{pH}$, calcium concentration, protein concentration and acid type. Caries Res 2008;42: 348-353.

Hughes JA, West NX, Parker DM, Newcombe RG, Addy M: Development and evaluation of a low erosive blackcurrant juice drink in vitro and in situ 1. Comparison with orange juice. J Dent 1999a;27:285-289.

Hughes JA, West NX, Parker DM, Newcombe RG, Addy M: Development and evaluation of a low erosive blackcurrant juice drink in vitro and in situ 3. Final drink and concentrate, formulae comparisons in situ and overview of the concept. J Dent 1999b;27:345-350.

Hughes JA, West NX, Parker DM, van den Braak $\mathrm{MH}$, Addy M: Effects of $\mathrm{pH}$ and concentration of citric, malic and lactic acids on enamel, in vitro. J Dent 2000;28:147-152.

- Jager DHJ, Vieira AM, Ruben JL, Huysmans MC: Influence of beverage composition on the results of erosive potential measurement by different measurement techniques. Caries Res 2008;42:98-104.

Jensdottir T, Bardow A, Holbrook P: Properties and modification of soft drinks in relation to their erosive potential in vitro. J Dent 2005; 33:569-575.

Jensdottir T, Holbrook P, Nauntofte B, Bucjwald C, Bardow A: Immediate erosive potential of cola drinks and orange juices. J Dent Res 2006;85:226-230.

Kielbassa AM, Shohadai SP, Schulte-Monting J: Effect of saliva substitutes on mineral content of demineralized and sound enamel. Support Care Cancer 2001;9:40-47. 
Larsen MJ: Prevention by means of fluoride of enamel erosion as caused by soft drinks and orange juice. Caries Res 2001;35:229-234.

-Larsen MJ, Nyvad B: Enamel erosion by some soft drinks and orange juices relative to their $\mathrm{pH}$, buffering effect and contents of calcium phosphate. Caries Res 1999;33:81-87.

Larsen MJ, Pearce EI: Saturation of human saliva with respect to calcium salts. Arch Oral Biol 2003;48:317-322.

Larsen MJ, Richards A: Fluoride is unable to reduce dental erosion from soft drinks. Caries Res 2002;36:75-80.

Lupi-Perugier L, Muller M, Leforestier E, Bertrand MF, Bolla M: In vitro action of Bordeaux red wine on the microhardness of human dental enamel. Arch Oral Biol 2003;48: 141-145.

Lussi A, Jaeggi T: Chemical factors; in Lussi A (ed): Dental Erosion. From Diagnosis to Therapy. Monogr Oral Sci. Basel, Karger, 2006, vol 20, pp 77-87.

Lussi A, Jäggi T, Schärer S: The influence of different factors on in vitro enamel erosion. Caries Res 1993;27:387-393.

Lussi A, Jaeggi T, Jaeggi-Schärer S: Prediction of the erosive potential of some beverages. Caries Res 1995;29:349-354.

Lussi A, Jaeggi T, Zero D: The role of diet in the aetiology of dental erosion. Caries Res 2004; 38(suppl 1):34-44.

Lussi A, Kohler N, Zero DT, Schaffner M, Megert B: A comparison of the erosive potential of different beverages in primary and permanent teeth using an in vitro model. Eur J Oral Sci 2000;108:110-114.
Mahoney E, Beattie J, Swain M, Kilpatrick N: Preliminary in vitro assessment of erosive potential using the ultra-micro-indentation system. Caries Res 2003;37:218-224.

McDonald JL, Stookey GK: Laboratory studies concerning the effect of acid-containing beverages on enamel dissolution and experimental dental caries. J Dent Res 1973;52:211216.

McNally LM, Barbour ME, O'Sullivan DJ, Jagger DC: An in vitro investigation of the effect of some analgesics on human enamel. J Oral Rehabil 2006;33:529-532.

Meyer-Lueckel H, Schulte-Monting J, Kielbassa AM: The effect of commercially available saliva substitutes on predemineralized bovine dentin in vitro. Oral Dis 2002;8:192-198.

Mok TB, McIntyre J, Hunt D: Dental erosion: in vitro model of wine assessor's erosion. Aust Dent J 2001;46:263-268.

Panich M, Poolthong S: The effect of casein phosphopeptide-amorphous calcium phosphate and a cola soft drink on in vitro enamel hardness. J Am Dent Assoc 2009;140:455460.

Parry J, Shaw L, Arnaud MJ, Smith AJ: Investigation of mineral waters and soft drinks in relation to dental erosion. J Oral Rehabil 2001; 28:766-772.

Pontefract H, Hughes J, Kemp K, Yates R, Newcombe RG, Addy M: The erosive effects of some mouthrinses on enamel. A study in situ. J Clin Periodontol 2001;28:319-324.

Rytömaa I, Meurman JH, Koskinen J, Laakso T, Gharazi L, Turunen R: In vitro erosion of bovine enamel caused by acidic drinks and other foodstuffs. Scand J Dent Res 1988;96:324333.
Shellis RP: A scanning electron-microscopic study of solubility variations in human enamel and dentine. Arch Oral Biol 1996;41: 473-484.

-Shellis RP, Finke M, Eisenburger M, Parker DM, Addy M: Relationship between enamel erosion and flow rate. Eur J Oral Sci 2005;113: 232-238.

-Shellis RP, Barbour ME, Jones SB, Addy M: Effects of $\mathrm{pH}$ and acid concentration on erosive dissolution of enamel, dentine and compressed hydroxyapatite. Eur J Oral Sci 2010; 118:475-482.

Stumm W: Chemistry of the Solid-Water Interface. New York, Wiley, 1992.

- Tantbirojn D, Huang A, Ericson MD, Poolthong $S$ : Change in surface hardness of enamel by a cola drink and a CPP-ACP paste. J Dent 2008;36:74-79.

West NX, Davies M, Amaechi BT: In vitro and in situ erosion models for evaluating tooth substance loss. Caries Res 2011;45(suppl 1):4352.

West NX, Hughes JA, Parker DM, Newcombe RG, Addy M: Development and evaluation of a low erosive blackcurrant juice drink in vitro and in situ. 2. Comparison with a conventional blackcurrant juice drink and orange juice. J Dent 1999;27:341-344.

West NX, Hughes JA, Addy M: The effect of $\mathrm{pH}$ on the erosion of dentine and enamel by dietary acids in vitro. J Oral Rehabil 2001;28: 860-864.

Wiegand A, Stock A, Attin R, Werner C, Attin T: Impact of the acid flow rate on dentin erosion. J Dent 2007;35:21-7. 